\title{
Overview of newer glucocorticosteroid preparations for inflammatory bowel disease
}

R BRATTSAND, PHD

ABSTRACT: Because the glucocorticosteroid receptor seems to be uniform in the human body, there is currently no support for a possibility of separating the therapeutic and adverse glucocorticosteroid actions at the receptor level. However, based on a new generation of glucocorticosteroids characterized by a high first pass metabolism in the liver, it seems possible today to reach a more selective topical therapy of inflammatory bowel disease. The properties of three new glucocorticosteroids are presented: the highly potent budesonide, fluticasone propionate and tixocortol pivalate - the latter with only low topical potency. Their properties can be exemplified by budesonide, which is currently the best documented compound. The topical potency of budesonide is 200 and 15 times higher than those of hydrocortisone and prednisolone, respectively. This means that there is a high potential for anti-inflammatory and immunosuppressive actions on rectal and bowel mucosa. The compound is metabolically stable in the bowel compartment, which allows full retention of glucocorticosteroid activity in the target organ. However, when absorbed and distributed to the liver, there is a $90 \%$ first pass hepatic metabolism to metabolites of very low potency. This suggests that after topical application to rectal or bowel mucosa, glucocorticosteroid activity in the systemic circulation is low. This is in contrast to prednisolone, which has a hepatic first pass metabolism of just $20 \%$. Can J Gastroenterol 1990;4(7):407-414 (pour résumé, voir page 408)

Key Words: Budesonide, Corticosteroids, Fluticasone, Tixocortol pivalate

AB Draco, Lund, Sweden

Correspondence and reprints: Dr Brattsand, AB Draco, Pharmacology 1, Box 34, S-221 00 Lund, Sweden
Qince Their inTRODUCtion as general anti-inflammatory agents in the early 1950s, the glucocorticosteroids are one of the mainstays in the therapy of active ulcerative colitis and Crohn's disease. It was found early that symptomatic improvement could be attained by daily treatment with $30 \mathrm{mg}$ or more of prednisolone (or its equivalent) administered via the oral and rectal routes. The therapeutic efficacy was confirmed by placebo controlled trials for ulcerative colitis in the mid 1950s, while it took a much longer time to attain such verification for Crohn's disease $(1-3)$.

\section{DEVELOPMENT OF CURRENT GLUCOCORTICOSTEROID THERAPY IN IBD}

The glucocorticosteroid era started with the introduction of cortisone, which is now known to be a prodrug with a very low affinity for the 


\section{Les derniers glucocorticostéroïdes et les maladies inflam- matoires de l'intestin}

RESUME: Parce que le récepteur des glucocorticostéroïdes semble uniforme dans tout l'organisme humain, il semble impossible de séparer les actions thérapeutiques et indésirables des glucocorticostéroïdes au niveau des récepteurs. Pourtant, grâce à une nouvelle génération de glucocorticostéroïdes caractérisés par un haut métabolisme de premier passage hépatique, on semble entrevoir l'éventualité d'une thérapie locale plus sélective dans les maladies inflammatoires de l'intestin. Les propriétés de trois de ces nouveaux médicaments sont présentées: le puissant budésonide, le propionate de fluticasone et le pivalate de tixocortol - ce dernier ne manifestant qu'une faible activité locale. Le mieux établi des trois, le budésonide sera examiné à titre d'exemple. L'activité locale du budésonide est de 200 à 15 fois supérieure à celle de l'hydrocortisone et de la prednisolone, respectivement. Cela signifie qu'il offre un potentiel anti-inflammatoire et immunosuppresseur élevé au niveau de la muqueuse rectale et intestinale. Le composé est métaboliquement stable dans le compartiment intestinal, ce qui autorise la pleine rétention de l'action glucocorticostéroïde au niveau de l'organe cible. Cependant, lorsqu'il est absorbé et parvient au foie, le produit est soumis à un métabolisme de premier passage de $90 \%$ et il se dégrade en métabolites de très faible puissance. Cela suggère qu'après application locale à hauteur du rectum et de l'intestin, l'activité systémique est faible. Ce résultat est à comparer à l'action de la prednisolone dont le métabolisme de premier passage est de l'ordre de $20 \%$.

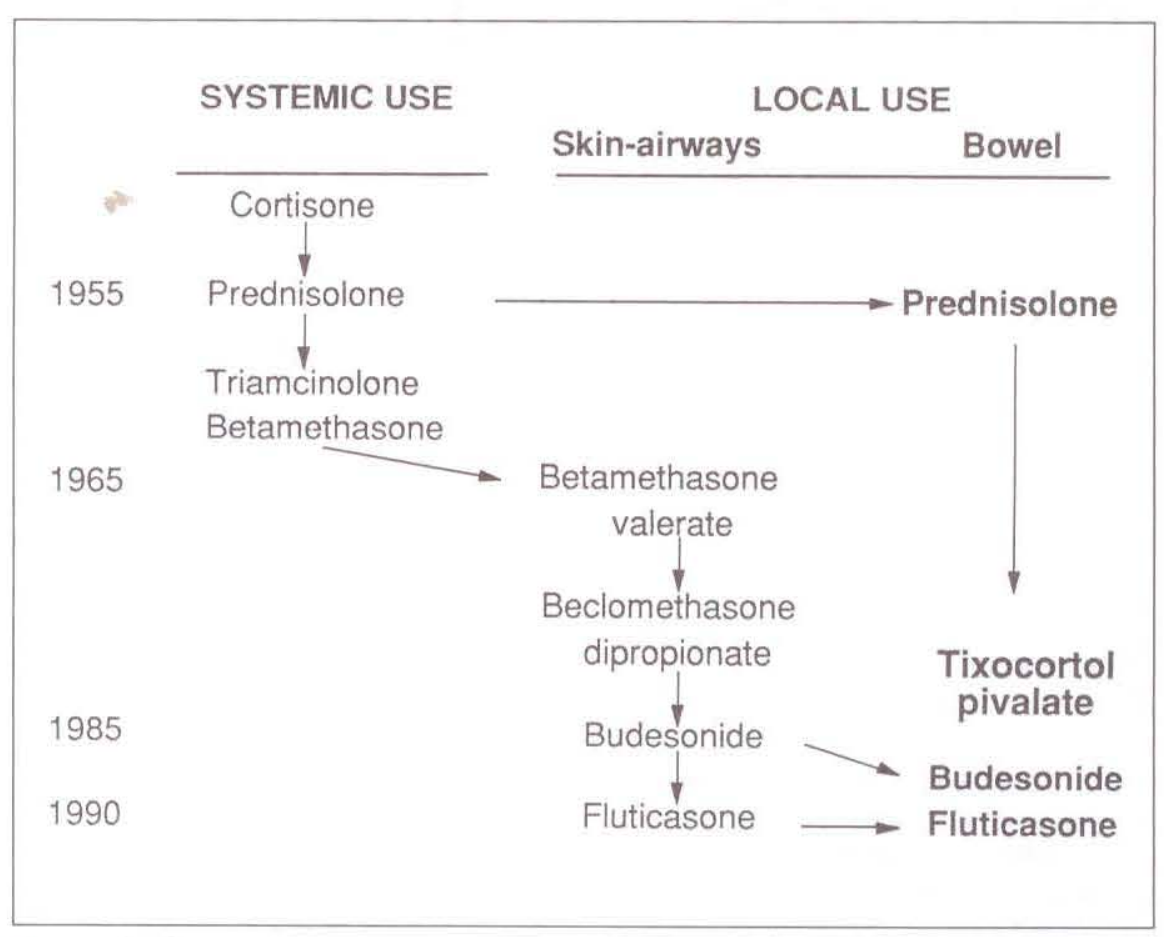

Figure 1) Schematic overview of glucocorticosteroid development

glucocorticosteroid receptor. Cortisone (or its close derivative, prednisone) has to be reduced in the liver to the corresponding $11-\mathrm{OH}$ compound hydrocortisone and prednisolone, respectively - to reach hormonal activity at the glucocorticoid and mineralocorticoid receptors. The chemical development of improved glucocorticosteroids for oral or other routes of systemic therapy culminated early with the introduction of prednisolone and 6-methylprednisolone, both having enhanced glucocorticoid but reduced mineralocorticoid activity. No major differentiation of the various glucocorticosteroid actions has been possible in systemic therapy, because all of these actions seem to be mediated via the same type of glucocorticosteroid receptor. To reduce the extent of serious adverse effects (eg, Cushing's syndrome, emotional disturbances, blocked hypothalmic-pituitary-adrenal axis, osteoporosis and connective tissue atrophy), high dose treatment with systemic glucocorticosteroid has to be limited to a few weeks and then tapered off to doses much lower than the 30 $\mathrm{mg} / \mathrm{kg}$ mentioned in the introduction.

It was shown early that proctitis and distal colitis could be treated topically using retention enemas or foams containing hydrocortisone or its 21 . ester $(4-7)$, or prednisolone or its 21 . ester $(8,9)$. The doses chosen for local therapy were similar to those used in systemic therapy (for hydrocortisone $100 \mathrm{mg}$ and for prednisolone 20 to 40 $\mathrm{mg})$. Therefore, it is not astonishing that it soon became apparent that this therapy was not just local, but - verified by depressed plasma cortisol levels provoked marked systemic actions (10. 14). Somewhat better selectivity for the rectal and sigmoid mucosa may be obtained by using prednisolone meta. sulphabenzoate, which is a larger molecule with a probably slower release of prednisolone (15). However, the site of that release is not yet known with certainty (15) and the conjugate may induce sulpha-like side effects (3). Today, it can be judged that if the medical aim is local therapy of bowel or rectal mucosa, hydrocortisone or pred. nisolone (or their esters) is not the right choice, as both hormones have too high systemic availability.

The aim of this paper is to describe the novel potential for a more selective topical therapy due to the forthcoming introduction of new glucocortico. steroids with high first pass metabolism in the liver. This drug development has not been primarily directed to inflam. matory bowel disease (IBD) but to an improved topical (inhalation) therapy of asthma and rhinitis. The main steps are schematically outlined in Figure 1. The first step was an increment of oral 
glucocorticosteroid potency of the prednisolone type of structure leading to potent but very biostable compounds like betamethasone, dexamethasone and triamcinolone. It was then possible to enhance the poor topical anti-inflammatory potency of these compounds by the introduction of lipophilic constituents in the 17-alpha and/or 16-alpha,17-alpha positions, resulting in the first topically potent 'skin' steroids betamethasone 17 valerate and triamcinolone acetonide. During that development the vasoconstriction (blanching) test on human skin was evolved as a rapid and relevant test in the judgement of topical glucocorticosteroid potency in man (16). Little attention was paid to the biotransformation rates and routes of these lipophilic glucocorticosteroids due to their restricted percutaneous absorption through the stratum corneum barrier. However, when betamethasone 17-alpha-valerate and the derivative beclomethasone 17-alpha, 21-dipropionate were inhaled for the topical treatment of asthma and rhinitis, the systemic glucocorticosteroid side effects were found to be surprisingly minute (17). This results from the fact that the liver, via its drug metabolizing enzymes (including the cytochrome P450 system), can more easily inactivate this lipophilic type of glucocorticosteroid structure than the less lipophilic structures of the parent molecules betamethasone, dexamethasone and triamcinolone $(17,18)$.

For glucocorticosteroid esters a clear distinction must be made between 17 . alpha and 21-esters. Esterification in the 17-alpha position enhances glucocorticosteroid potency markedly (16), while 21-esters have unaltered or even reduced activity. Furthermore, the 17 alpha but not the 21-ester bond is rather stable in extrahepatic tissue, eg, airways and intestinal walls (18). This suggests that at the site of local application, 17-alpha-esters can exert strong glucocorticosteroid activity, which on the other hand can be reduced in the systemic compartment via hepatic biotransformation. This improved profile of 17-alpha over 21-esters has been demonstrated also for the rectal mucosa. Enemas containing betamethasone 21-phosphate provoked systemic actions even at the minimum dose for therapeutic efficacy (19). On the other hand, enemas containing betamethasone 17-alpha-valerate (20) or beclomethasone 17-alpha,21-dipropionate $(21-24)$ were reported to induce less plasma cortisol depression than that obtained with therapeutically equipotent prednisolone or betamethasone 21-phosphate enemas.

As shown in Figure 1, the developmental line that started with betamethasone valerate and beclomethasone dipropionate has now been reinforced with new topical glucocorticosteroids - eg, budesonide $(25,26)$ and fluticasone propionate $(27,28)$. The latter two glucocorticosteroids have from the beginning been designed and selected for a high first pass metabolism in the liver, and their properties are described in more detail below.

\section{SELECTION OF OPTIMAL GLUCOCORTICOSTEROID PROFILE FOR TOPICAL THERAPY OF BOWEL AND RECTUM}

The general opinion is that most specific glucocorticosteroid actions are mediated via triggering of glucocorticosteroid receptors. When a glucocorticosteroid agonist is bound by the receptor, there is a conformational change in the steroid-receptor complex and a translocation of the complex to glucocorticosteroid-responsive elements in the genome. By modulation at these sites there is enhanced or reduced transcription of mRNA for glucocortico-steroid sensitive proteins (29). The transcription and translation of some peptides or proteins are strongly suppressed by glucocorticosteroid (eg, most interleukins) while other proteins are reinforced (eg, beta-receptors, surfactant, angiotensin converting enzyme, growth hormone and metallothionin). The varying combination of enhanced and reduced transcription leads to the wide spectrum of glucocorticosteroid actions, eg, anti-inflammatory actions, immunosuppression, local or systemic catabolic actions, etc. The glucocorticosteroid receptor seems to be uniform in the human body (30), which means that the same receptor type - depending on its cellular location - can mediate therapeutic as well as adverse glucocorticosteroid reactions. Thus, there is currently no possibility of separating the various glucocorticosteroid actions via subtypes of glucocorticosteroid receptors. However, for organs accessible to local therapy, a better way to achieve separation is to deposit a restrictive quantity of selected glucocorticosteroids directly in the organ, and thus reduce the adverse effects originating from bulk glucocorticosteroids distributed from a high systemic bolus. One recent example is glucocorticosteroid inhalation for the topical treatment of asthma and rhinitis $(17,26)$, which has more or less revolutionized the therapy of moderate and severe asthma. No corresponding clinical development has occurred for the topical treatment of IBD, which at least to some extent-may depend on the wrong glucocorticosteroid having been exploited. In theory, with the right glucocorticosteroid the prospects are better for the development of a selective topical therapy for the bowel than for the airways. This is due to the fact that these glucocorticosteroids are inactivated by biotransformation mainly in the liver $(18,31,32)$. When absorbed from the bowel compartment, nearly all of the drug has to pass through the liver and its specialized drug metabolizing systems before being distributed in the systemic circulation. However, when the inhaled drug is absorbed from the airway mucosa it reaches the heart first and only approximately one-third will have first pass access to the liver.

Thus in theory, the optimal glucocorticosteroid profile for topical antiinflammatory immunosuppressive therapy of IBD is a compound with high topical glucocorticosteroid potency and with rather high metabolic stability in the bowel and rectum compartments - the latter property to secure full activity in the target organ. On the other hand, the compound should have $100 \%$ first pass metabolism in the liver.

The new glucocorticosteroids will 


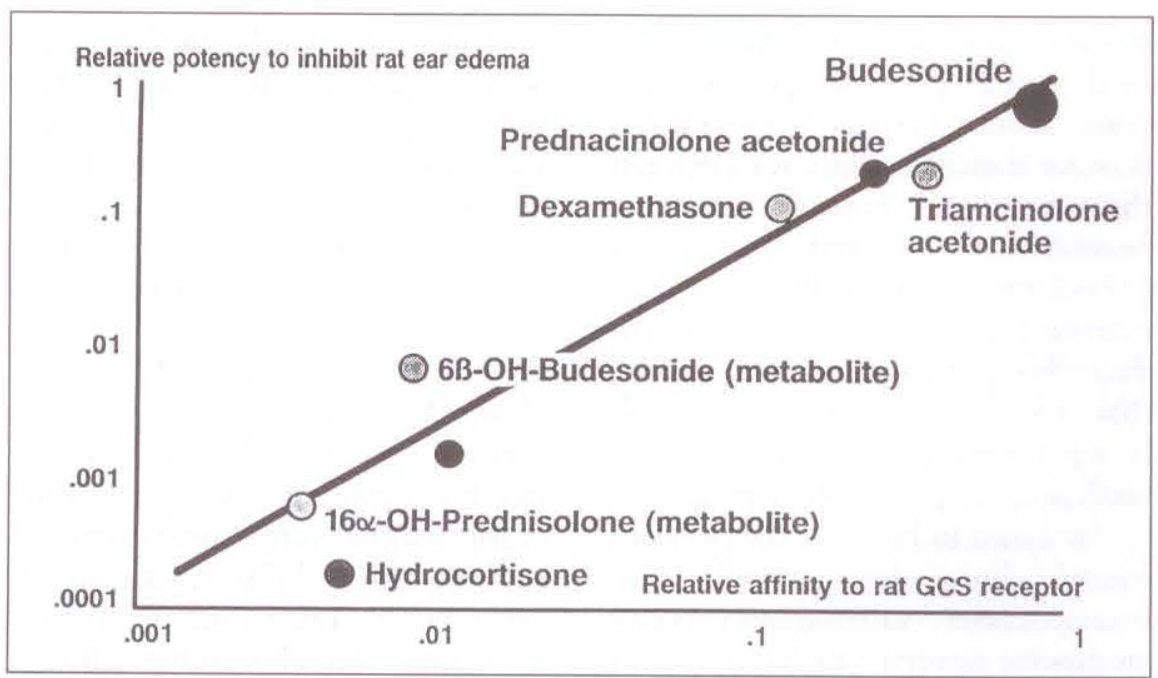

Figure 2) Close correlation between affinity for glucocorticosteroid receptor (in vitro) and topical antiedema potency (in vivo). Based on studies in rats $(52,53)$

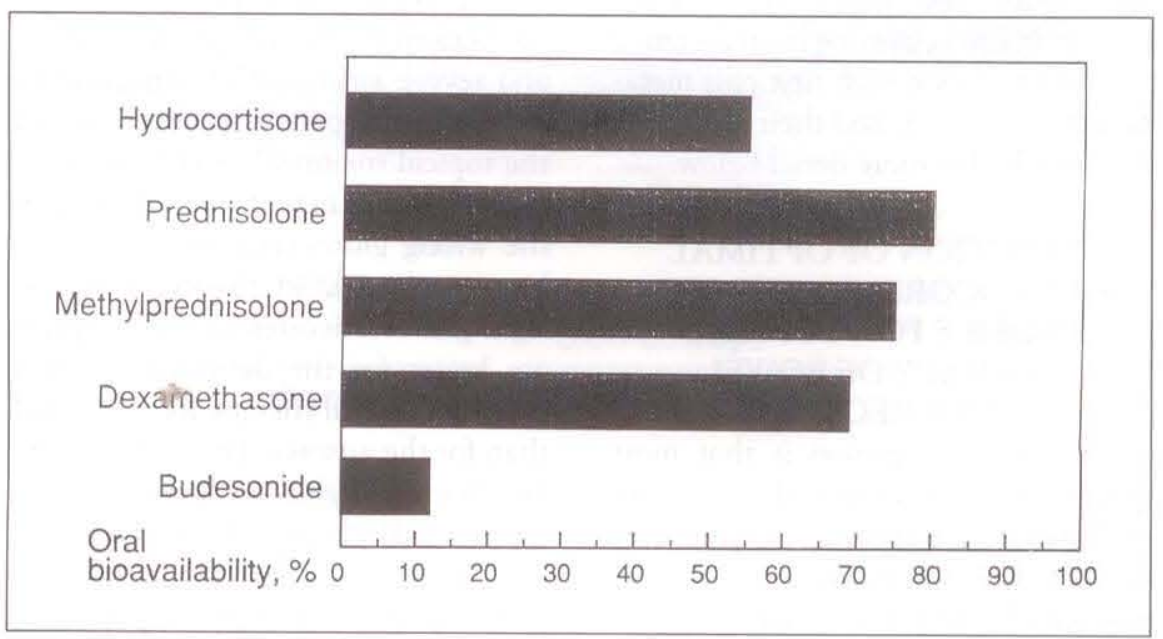

Figure 3) Oral bioavailability (\%) in humans. Based on Table 7 in reference 55 , which summarizes the human studies published (hydrocortisone one study, prednisolone seven, methylprednisolone two, dexamethasone four, budesonide two)

be judged according to these criteria. Topical potency is estimated by two parameters. One is the relative affinity for glucocorticosteroid receptors, determined in subcellular systems with little possibility of metabolic inactivation. As determined in rat models, in a series of eight glucocorticosteroids not inactivated in the target organ, there is a close correlation between receptor affinity and topical anti-inflammatory potency (Spearman's rank order correlation coefficient 0.98 ) (Figure 2). The other estimation of topical glucocorticosteroid potency is activity in the vasoconstriction test (16). In this test, ethanolic solutions of the glucocorticosteroid are applied to human skin under occlusion to facilitate percutaneous absorption.

What level of glucocorticosteroid potency is optimally required for the topical treatment of IBD? The efficacy of enemas with hydrocortisone (4-7) and prednisolone $(8,9,13)$ suggests that low glucocorticosteroid potency is sufficient to alleviate the symptoms of proctitis and left-sided colitis. However, little is as yet known regarding to what extent intense glucocorticosteroid treatment by more potent enema preparations will induce a more complete and longlasting healing of lesions. The study by Danielsson et al (13) illustrates that it is possible to reach better symptomatic and objec- tive healing with a potent preparation (budesonide) than with prednisolone.

Furthermore, the most exciting medical aim for improved topical IBD therapy is to reach topical (local) selectivity for the ileal and colonic bowel walls via retarded oral formulations. Ideally, such a formulation should release the active glucocorticosteroid just within the bowel segments most often affected by Crohn's disease and ulcerative colitis. It is still poorly known how deep the submucosal penetration must be for optimal 'topical' therapy. In Crohn's disease it has been proposed that the tissue infarction starts with vascular injury and arterial occlusion at the level of the muscularis propria (33), which would suggest that high anti-inflammatory activity is desired also in the deep compartments of the bowel wall. A retarded oral formulation for the selective treatment of the bowel should therefore release a potent glucocorticosteroid with sufficient water and lipid solubility to allow its dissolution as well as its effective absorption deep into the bowel wall. Ideally, the glucocorticosteroids should have a high affinity for the bowel tissue and thus stay long in that compartment. Another reason for selecting highly potent glucocorticosteroids for retarded oral formulations is that, due to the risk of present or forthcoming luminal strictures in Crohn's disease, the tablets should be small.

However, to achieve improved topical therapy of IBD, the main medical aim is to select a glucocorticosteroid with a much higher first pass metabolism than that of prednisolone (Figure 1). A high first pass metabolism in the intestinal-liver compartment is reflected as a low systemic availability via the rectal or oral routes. Therefore, in the following discussion, oral or rectal bioavailability is used as a parameter of unwanted systemic activity.

\section{PROFILE OF NEW \\ GLUCOCORTICOSTEROIDS}

Table 1 describes the structures and topical potencies of the new glucocorticosteroids. The topical potency (receptor affinity and vasoconstriction activity) is given in relation to 
TABLE 1

Newer glucocorticosteroid substances for inflammatory bowel disease

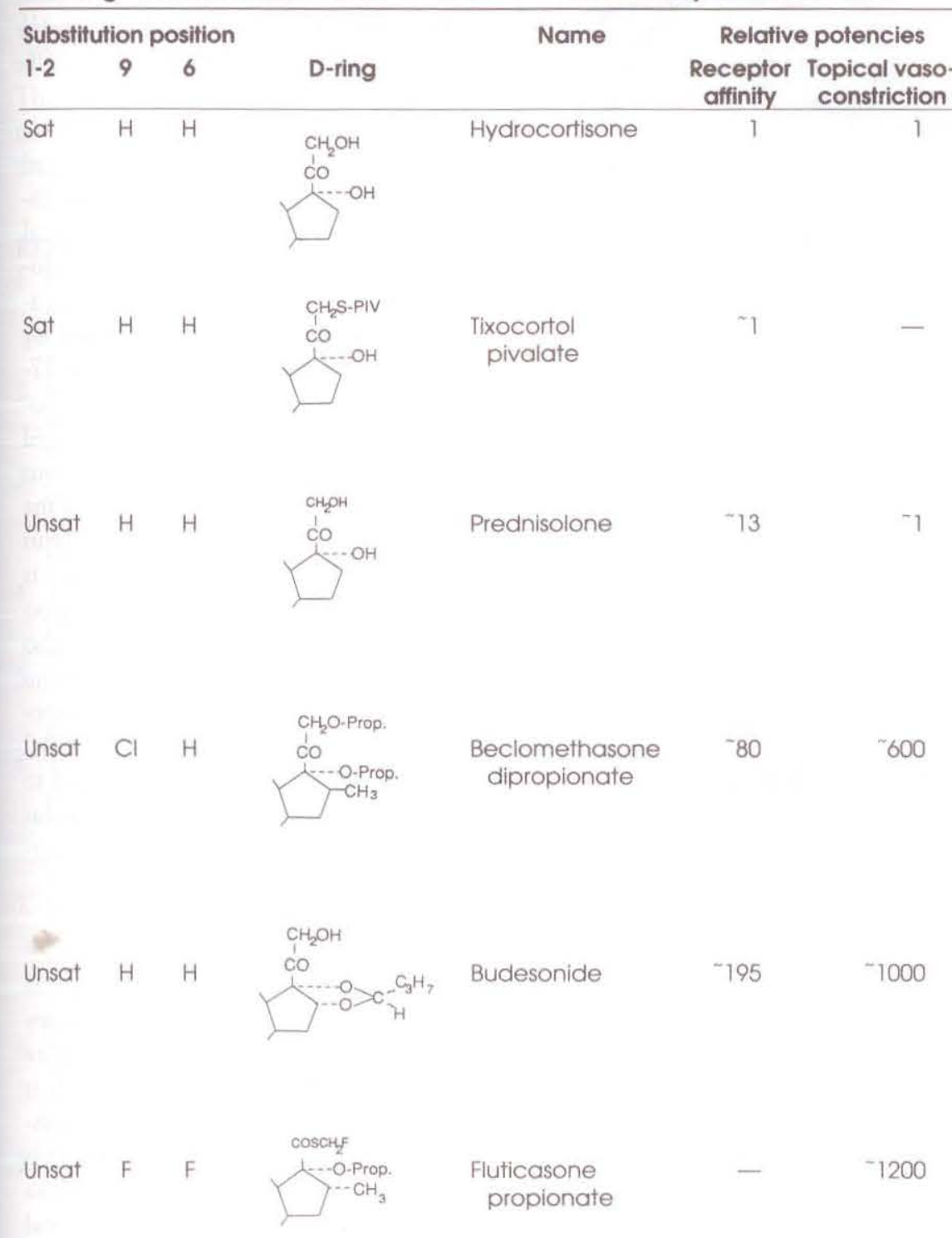

Structure and topical glucocorticosteroid potencies of glucocorticosteroids of current interest in the topical treatment of inflammatory bowel disease. The topical glucocorticosteroid potency is given as affinity for the glucocorticosteroid receptor and as topical vasoconstriction activity - both in relation to hydrocortisone. Sat Saturated bond in the 1-2 position: Unsat Unsaturated (double) bond in the 1-2 position. Based on the following references: tixocortol pivalate (34), prednisolone (in the files of Draco and 54), beclomethasone dipropionate $(17,42,48,54)$, budesonide (42.54), fluticasone propionate (48)

hydrocortisone. Hydrocortisone has a low topical potency (Table 1) and its oral bioavailability is approximately $50 \%$ (Figure 3). The latter figure means that half of orally (and probably rectal. ly) administered hydrocortisone passes intact into the systemic circulation. Prednisolone has a somewhat higher receptor affinity (approximately 10 times that of hydrocortisone) (Table 1) but also a clearly higher oral bioavailability (approximately $80 \%$ ) than that of hydrocortisone (Figure 3). This means that with prednisolone the prospects of a selective therapy of the bowel are even more lacking.

Tixocortol pivalate is a late development from the hydrocortisone structural line. By changing the 17-beta side chain of the D-ring from $-\mathrm{COCH}_{2} \mathrm{OH}$ to $-\mathrm{COCH}_{2} \mathrm{SH}$ and esterifying the thiol group with pivalinic acid, the thioester tixocortol pivalate was obtained (Table 1). This change has not enhanced receptor affinity over that of hydrocortisone (34), and as an enema preparation even higher doses (250 $\mathrm{mg}$ ) than those in the latter reference are used (35-37). The interesting property of the substance is its high first pass metabolism, leading to a bioavailability of 10 to $20 \%$. In man the acute intrarectal administration of 500 to $2000 \mathrm{mg}$ tixocortol pivalate did not markedly affect plasma or urinary cortisol levels (39). It should be added that these doses were given in the morning, when the body is less sensitive to external glucocorticosteroids than compared to the late evening. However, under the experimental conditions used, a 5 $\mathrm{mg}$ betamethasone 21-phosphate enema strongly reduced cortisol levels (39). By saturation and reduction of the A-ring and rearrangement of the thiol bond, tixocortol pivalate is biotransformed into metabolites with low glucocorticosteroid activities $(38,40)$. Animal studies demonstrate that the plasma clearance of tixocortol pivalate is very high, demonstrating an extensive extrahepatic metabolism (38). This is supported by in vitro studies showing that the erythrocyte enzyme S-methyltransferase can rearrange the thiol bond of tixocortol pivalate (38). This rapid extrahepatic metabolism may result in partial inactivation in the target organ, which might lead to even lower potency in the bowel wall than the low figure given in Table 1 . Restricted intestinal absorption may also contribute to low therapeutic activity, since 2 to $42 \%$ of the dose given was found unchanged in human feces (38). Thus, in theory tixocortol pivalate has an improved profile for the selective glucocorticosteroid treatment of proctitis and left-sided colitis, but more studies are required to judge its therapeutic potency on that indication. Its very low topical potency excludes its use via retarded oral formulations.

The 17-alpha substituted glucocorticosteroids, beclomethasone dipropionate, budesonide and fluticasone propionate (Table 1) all have intrinsic 


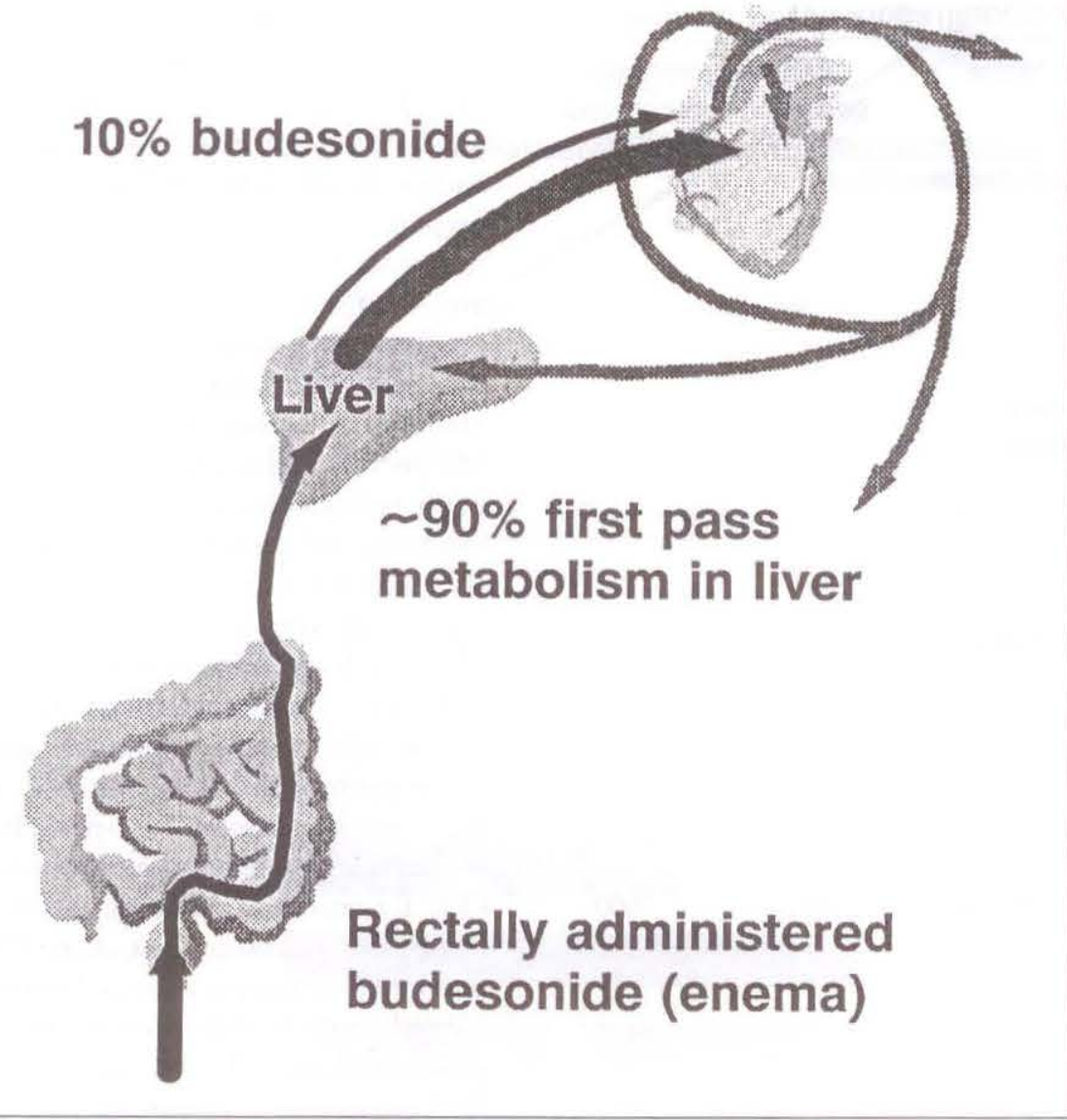

Figure 4) Summary of human pharmacokinetics of budesonide when applied to bowel mucosa

activities at least 100 times greater than those of hydrocortisone and tixocortol pivalate, and all three are inactivated by liver biotransformation alone. Beclomethasone dipropionate enemas are reported to be active in proctosigmoiditis at doses of 2 to $5 \mathrm{mg}$ with little systemic activity (14,21-24). Beclomethasone dipropionate and its first hydrolysis product - the corresponding 17-alpha monopropionate with a glucocorticosteroid activity of at least the same order as that of the parent compound - are biotransformed by the liver to beclomethasone and oxidative products $(18,31,41)$. One of the metabolites is beclomethasone, which retains clear glucocorticosteroid activity (42). There is no published figure for the oral or rectal bioavailability of beclomethasone dipropionate in man. Budesonide has double the topical potency of beclomethasone dipropionate, which means about 200 and 15 times those of hydrocortisone and pred- nisolone, respectively (Table 1). An enema preparation with budesonide 2 $\mathrm{mg}$ induced more rapid objective and subjective healing of active distal ulcerative colitis than that achieved with $31 \mathrm{mg}$ prednisolone 21-phosphate (13). One physiochemical advantage of budesonide is its water solubility (14 $\mu \mathrm{g} / \mathrm{mL}), 100$ times higher than beclomethasone dipropionate and fluticasone propionate. This will facilitate its dissolution and transport into the bowel wall; budesonide seems to be efficiently absorbed after rectal as well as oral administration (in the files of Draco). Budesonide is rapidly biotransformed in the liver by oxidative biotransformation into metabolites which have at least 100 times lower intrinsic glucocorticosteroid potencies than that of the intact compound $(41,43-45)$. The plasma clearance in humans is about $1.2 \mathrm{~L} / \mathrm{min}$, which means an approximately five times higher clearance than that of predni- solone $(0.23 \mathrm{~L} / \mathrm{min})$. The oral bioavailability of budesonide in humans is about 10\% (Figure 3) and the rectal bioavailability approximately 15\% $(46,47)$.

Fluticasone propionate (Table 1) is a 17-alpha propionate with an unusual side chain in the 17-beta position (S. fluoromethyl carbothioate). Its topical potency is double that of beclomethasone dipropionate (48). Fluticasone propionate is biotransformed by the liver through hydrolysis of the 17 . beta carbothioate group into metabolites with low glucocorticosteroid potencies $(48,49)$. After intravenous injection into humans its plasma clearance is approximately $0.9 \mathrm{~L} / \mathrm{min}$ (48). The oral bioavailability is proposed to be very low, depending on hepatic first pass metabolism, but also on low (less than 50\%) absorption from the intestines leading to marked excretion of intact substance. The partial intestinal absorption may be related to low water solubility, impairing dissolution and transport into the mucosal surface.

\section{CONCLUSIONS}

Figure 4 summarizes the prospects for more selective topical IBD therapy by new glucocorticosteroids. The figure is exemplified by budesonide, which is currently the best documented compound. Via the rectal or oral route it is possible to deliver to the bowel mucosa a glucocorticosteroid with a topical anti-inflammatory potency approximately 200 times that of hydrocortisone. Based on the $T_{\max }$ in plasma the dwell time in the bowel compartment is estimated to be one to a few hours, which is a sufficiently long period for the triggering of important anti-inflammatory actions $(50,51)$. When passing through the liver, there is a $90 \%$ first pass metabolism delivering only about $10 \%$ of intact glucocorticosteroid to the systemic circulation.

Enhanced drug selectivity for the bowel compartment can be exploited therapeutically in two ways. The reduced risk of serious adverse reactions outside the target area makes protracted therapeutic or even prophylactic treatment more possible. En. 
hanced selectivity can also allow more intense treatment of the diseased areas, which may lead to more rapid and possibly even more longstanding healing. The next few years will show whether one or both of these approaches will be therapeutically useful.

\section{REFERENCES}

1. Jewell DP. Corticosteroids for the management of ulcerative colitis and Crohn's disease. Gastroenterol Clin North Am 1989;18:21-34.

2. Meyers S, Sachar DB. Medical management of Crohn's disease. Hepatogastroenterology 1990;37:42-55.

3. Mulder CJJ, Rindas AALM, Wiltink EHH, Tytgat GNJ. Topical corticosteroids in inflammatory bowel disease. Neth J Med 1989;35:S27-34.

4. Truelove SC. Treatment of ulcerative colitis with local hydrocortisone. Br Med J 1956;2:1267-72.

5. Truelove SC. Treatment of ulcerative colitis with local hydrocortisone. Br Med J 1957;1:1437-43.

6. Truelove SC. Treatment of ulcerative colitis with local hydrocortisone hemisuccinate sodium: A report on a controlled therapeutic trial. Br Med J 1958;2:1072-7.

7. Watkinson G. Treatment of ulcerative colitis with topical hydrocortisone hemisuccinate sodium: A controlled trial employing restricted sequential analysis. Br Med J 1958;2:1077-82.

8. Matts SGF. Intrarectal treatment of 100 cases of ulcerative colitis with prednisolone 21-phosphate retention enemata. Br Med J 1961;1:165

9. MacDougal I. Treatment of ulcerative colitis with rectal steroids. Lancet 1963;i:826-7.

10. Spencer JA, Krisner JB. Experience with short and long term courses of local adrenal steroid therapy for ulcerative colitis. Gastroenterology 1962;6:669-77.

11. Farmer RG, Schumacher OP. Treatment of ulcerative colitis with hydrocortisone enemas: Relationship of hydrocortisone absorption, adrenal suppression and clinical response. Dis Colon Rectum 1970;13:355-61.

12. Cann PA, Holdsworth CD. Systemic absorption from hydrocortisone foam enema in ulcerative colitis. Lancet 1987;i:922-3.

13. Danielsson A, Hellers G, Lyrenäs E, et al. A controlled trial of budesonide versus prednisolone retention enemas in active distal ulcerative colitis. Scand J Gastroenterol 1987;22:987-92.

14. Van der Heide H, Van den BrandtGrädel V, Tytgat GNJ, et al. Comparison of beclomethasone dipropionate and prednisolone 21 phosphate enemas in the treatment of ulcerative proctitis. J Clin

Gastroenterol 1988;10:169-72.

15. Lee DAH, Taylor M, James VTH, Walker G. Rectally administered prednisolone evidence for a predominantly local action. Gut 1980;21:215-8.

16. McKenzie AW. Percutaneous absorption of steroids. Arch Dermatol 1962;86:611

17. Mygind N, Clark TJH. Topical Steroid Treatment for Asthma and Rhinitis. London: Baillière Tindall, 1980:3447,66-76.

18. Martin L, Harrison C, Tanner RJN. Metabolism of beclomethasone dipropionate by animals and man. Postgrad Med J 1975;51(Suppl 4):11-20.

19. Matts SGF. Betamethasone enemata in ulcerative colitis. Gut 1962;3:312-4

20. Lennard-Jones JE. Betamethasone 17 . valerate and prednisolone 21-phosphate retention enemata in proctocolitis. Br Med J 1971;3:84-6.

21. Kumana CR, Seaton T, Meghji M, Casteli M, Benson R, Sivakumaran T. Beclomethasone dipropionate enemas for treating inflammatory bowel disease without producing Cushing's syndrome or hypothalamic-pituitary-adrenal suppression. Lancet 1982;i:579-83.

22. Levine DS, Rubin CE. Topical beclomethasone dipropionate enemas improve distal ulcerative colitis and idiopathic proctitis without systemic toxicity. Gastroenterology 1985;88:1473A.

23. Van der Heide H, Mulder CJJ, Wiltnik EHH, Endert E, Houthoff HJ, Tytgat GNJ. Comparison of enemas containing BDP or PF in the treatment of distal ulcerative colitis. Gastroenterology 1987;92:A1679.

24. Bansky G, Buhler H, Stamm B, Häcki WH, Buchmann P. Treatment of distal ulcerative colitis with beclomethasone enemas: High therapeutic efficacy without endocrine side effects. Dis Colon Rectum 1987;30:288-92.

25. Brattsand R, Thalén A, Roempke K, Källsträm L, Gruvstad E. Development of glucocorticosteroids with a very high ratio between topical and systemic activities. Eur J Respir Dis 1982;63(Suppl 122):62-73

26. Clissold SP, Heel RC. Budesonide. A preliminary review of its pharmacodynamic properties and therapeutic efficacy in asthma and rhinitis. Drugs 1984;28:485-518.

27. Bauer K, Bamtje TA, Sips AP, et al. The effect of inhaled fluticasone propionate, a new potent corticosteroid in severe asthma. Eur Respir J 1988;2:201A.

28. Harding SM, Felstaed S. A comparison of the tolerance and systemic ef- fects of fluticasone propionate and beclomethasone dipropionate in healthy volunteers. Eur Respir ] 1988;2:196A.

29. Fahey JV, Guyre PM, Munck A. Mechanisms of anti-inflammatory actions of glucocorticoids. In: Weissman $\mathrm{G}$, ed. Advances in Inflammation Research, Vol 2. New York: Raven Press 1981:21-51.

30. Gustafsson J , Carlstedt-Duke J, Strömstedt P-E. Structure, function and regulation of the glucocorticoid receptor. In: Sato GH, Stevens JL, eds. Molecular Endocrinology and Steroid Hormone Action. New York: Alan R Liss, 1990:65-82.

31. Martin LE, Tanner RJN, Clark TJH, Cochrane MB. Absorption and metabolism of orally administered beclomethasone dipropionate. Clin Pharmacol Ther 1974;15:267-75.

32. Andersson P, Edsbäcker S, Ryrfeldt A, von Bahr C. In vitro biotransformation of glucocorticoids in liver and skin homogenate fraction from man, rat and hairless mouse. J Steroid Biochem 1982;16:787-95.

33. Wakefield AJ, Dhillon AP, Rowels PM, Sawyer AM, Pittilo RM, Lewis AAM. Pathogenesis of Crohn's disease: Multifocal gastrointestinal infarction. Lancet 1989;ii:1057-62.

34. Junien JL. Pharmacology of tixocortol pivalate, a glucocorticoid belonging to the 21-thiosteroid family. In: Henry JF, ed. 1st Meeting 21-thiosteroids. Mediators of Inflammation: The Local Response. Montrouge: John Libbey Eurotext, 1988:65-70.

35. Friedman G. Treatment of refractory proctosigmoiditis and left sided colitis with a rectally instilled nonmineralocorticoid steroid. Gastroenterology 1985;88:1388A.

36. Levinsson P. Tixocortol pivalate versus hydrocortisone enemas in ulcerative colitis: A multicenter comparative clinical trial. IBD symposium. April 12, 1985, Phoenix AZ, USA.

37. Hanauer SB, Kirsner JB, Barrett WE. The treatment of left-sided ulcerative colitis with tixocortol pivalate. Gastroenterology 1986;90:1449A.

38. Chanoine F. Tixocortol pivalate: Pharmacokinetics and metabolism. In: Henry JF, ed. 1st Meeting 21-thiosteroids. Mediators of Inflammation: The Local Response. Montrouge: John Libbey Eurotext, 1988:71-82.

39. Larochelle P, Du Sowich P, Bolte E, Lelorier J, Goyer R. Tixocortol pivalate, a corticosteroid with no systemic glucocorticoid effect after oral, intrarectal and intranasal applications. Clin Pharmacol Ther 1983;33:343-50.

40. Lelièvre $\mathrm{V}$, Bertin $\mathrm{B}$, Chanoine $\mathrm{F}$, Buré 
J, Junien JL. Correlation between binding activity, inhibition of lymphoblastic transformation and metabolism of tixocortol 21-pivalate in mouse thymocytes. Agents Actions 1987;21:262-5.

41. Andersson PH, Ryrfeldt $\AA$. Biotransformation of the topical glucocorticoids budesonide and beclomethasone $17 \alpha, 21$-dipropionate in human liver and lung homogenate. J Pharm Pharmacol 1984;36:763-5.

42. Axelsson B, Brattsand R, Andersson PH, Ryrfeldt $\AA$, Thalén A. Relationship between glucocorticosteroid effects of beclomethasone $17 \alpha, 21$-dipropionate, beclomethasone $17 \alpha$-propionate and beclomethasone as studied in human, mouse and rat tissue. Respiration 1984;46(Suppl 1):4.

43. Edsbäcker S, Jösson S, Lindberg C, Ryrfeldt $\AA$, Thalén A. Metabolic pathways of the topical glucocorticoid budesonide in man. Drug Metab Dispos 1983;11:590-6.

44. Edsbäicker S, Andersson P, Lindberg C, Ryrfeldt A, Thalén A. Metabolic acetal splitting of budesonide - A novel inactivation pathway for topical glucocorticoids. Drug Metab Dispos 1987;15:412-7.
45. Edsbäcker S, Andersson P, Lindberg C, Paulsson J, Ryrfeldt $\AA$, Thalén A. Liver metabolism of budesonide in rat, mouse and man. Comparative aspects. Drug Metab Dispos 1987;15:403-11.

46. Ryrfeldt $\AA$, Andersson $\mathrm{PH}$, Edsbäcker S, Tönnesson M, Davies D, Pauwels R. Pharmacokinetics and metabolism of budesonide, a selec tive glucocorticoid. Eur J Respir Dis 1982;63(Suppl):86-95.

47. Edsbäcker S, Johansson S-Å. Correlation between kinetic properties and clinical safety of budesonide enema. World Congress of Gastroenterology Sydney, Australia 1990, Abstract PD 561

48. Harding S. Human pharmacology of fluticasone. XIVth Congress of the European Academy of Allergology and Clinical Immunology, Berlin (West), Sept 17-22, 1989. AS 04.04.

49. Ayrton J, Engllish AF, MacLean AV. Preclinical development of fluticasone propionate. Eur Resp J 1990;3:922

50. Miller-Larsson A, Brattsand R. Topical anti-inflammatory activity of the glucocorticoid budesonide on airway mucosa. Evidence for a "hit and run" type of activity. Agents Actions 1990;29:127-9.
51. Brattsand R, Pipkorn U. Glucocorticoids: Experimental approaches. In: Kaliner M, Barnes P, Persson CG, eds, Asthma and Airway Hyperresponsiveness. New York: Marcel Dekker, 1990:667-709.

52. Dahlberg E, Thalén A, Brattsand R, et al. Correlation between chemical structure, receptor binding and biological activity of some novel, highly active $16 \alpha, 17 \alpha$-acetal-substituted glucocorticoids. Mol Pharmacol 1984;25:70-8.

53. Brattsand $\mathrm{R}_{3}$ Andersson PT, Edsbäcker S, Ryrfeldt A. Development of glucocorticosteroids with lung selectivity. In: Ellul-Micallef E, Lam WK, Toogood JH, eds. Advances in the Use of Inhaled Corticosteroids. Amsterdam: Excerpta Medica 1987:60-78.

54. Johansson S- $\AA$, Andersson K-E, Brattsand R, Gruvstad E, Hedner P. Topical and systemic glucocorticoid potencies of budesonide, beclomethasone dipropionate and prednisolone in man. Eur J Respir Dis 1982;63(Suppl 122):74-82.

55. Edsbäcker S. Studies on the Metabolic Fate and Human Pharmacokinetics of Budesonide. University of Lund, Thesis, 1986:39. 


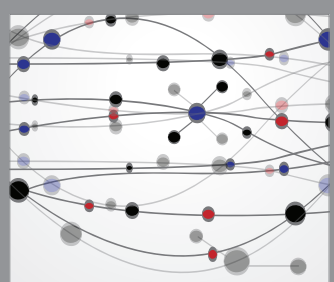

The Scientific World Journal
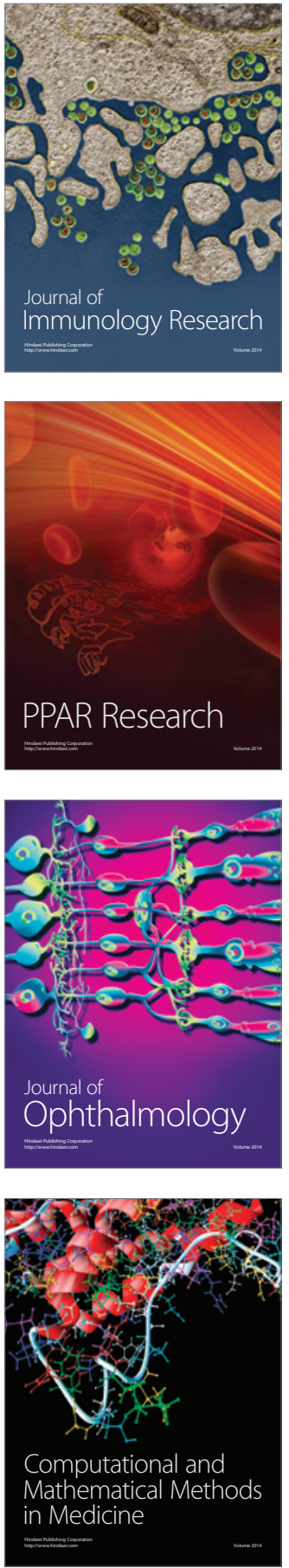

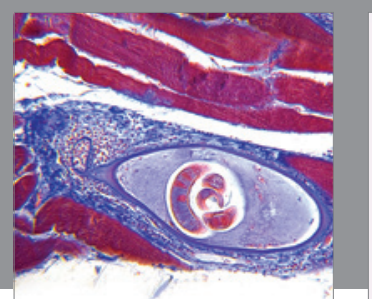

Gastroenterology Research and Practice

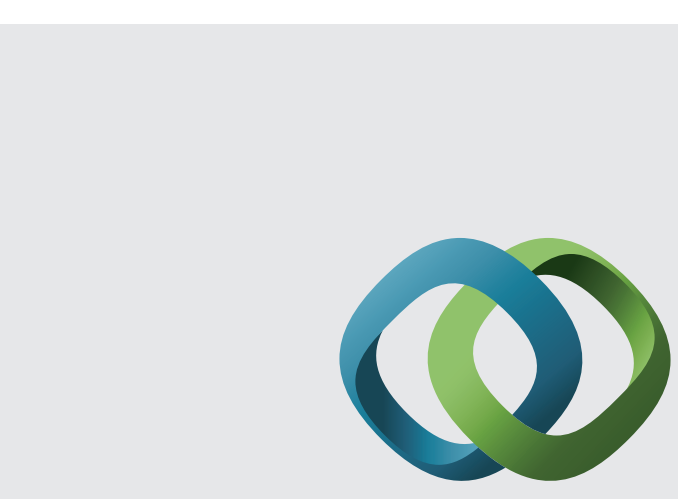

\section{Hindawi}

Submit your manuscripts at

http://www.hindawi.com
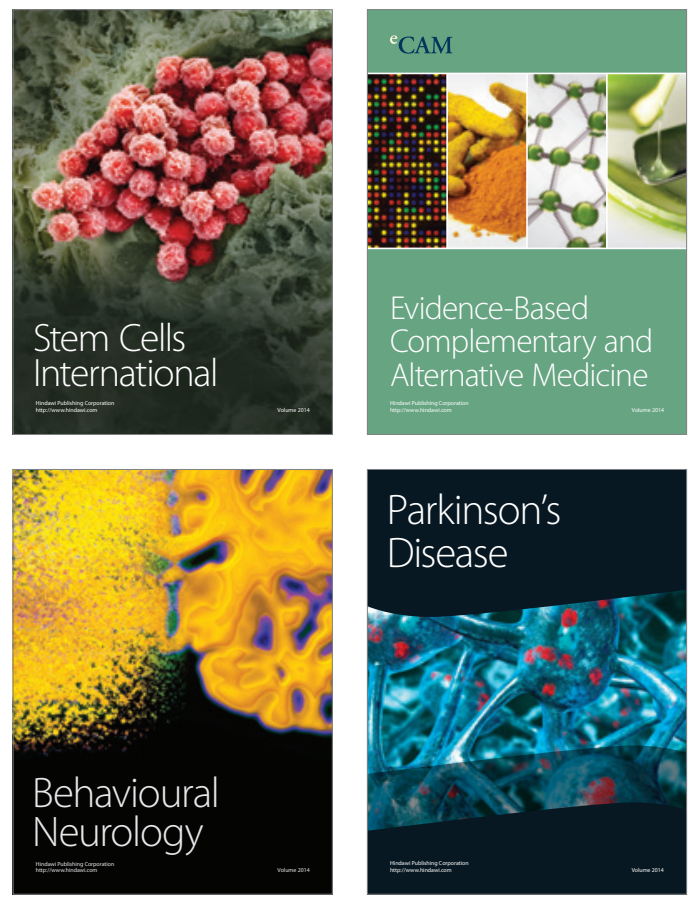
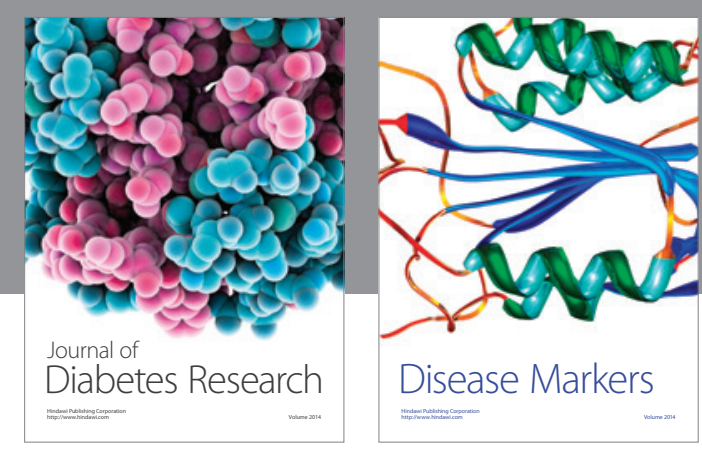

Disease Markers
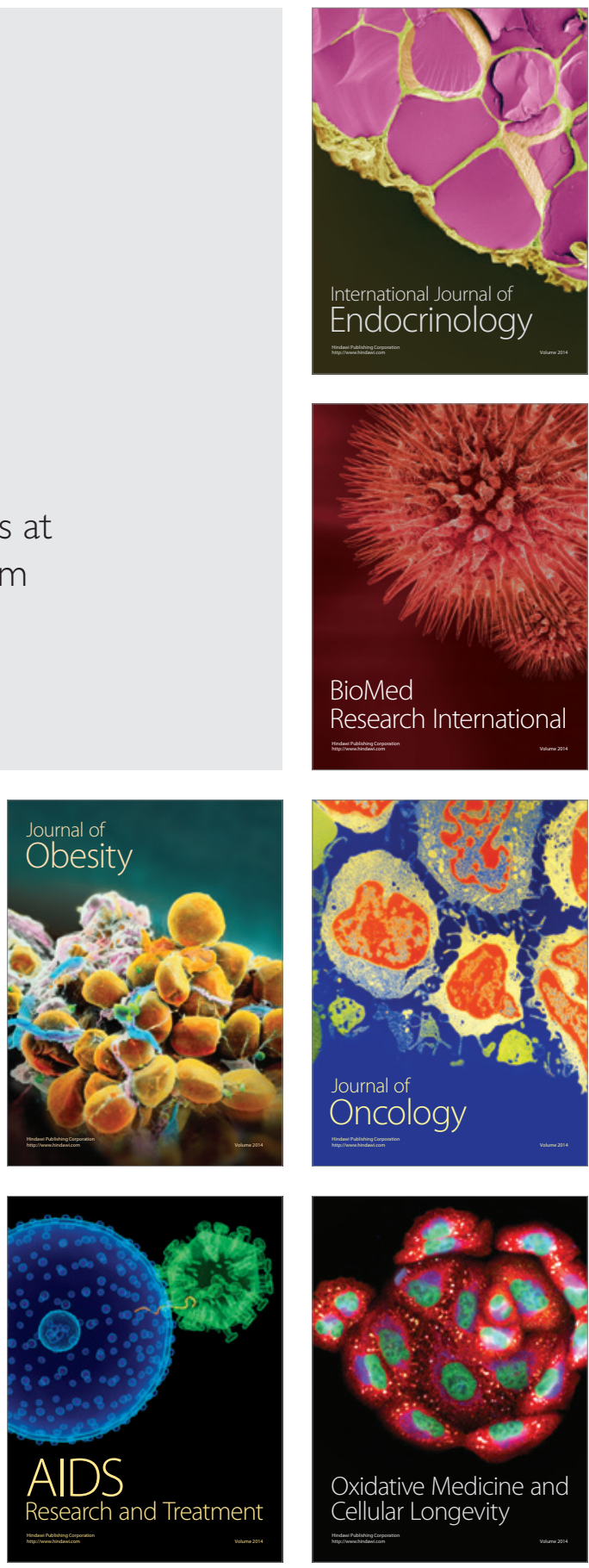